\title{
BMJ Open Biopsychosocial implications of living with multiple sclerosis: a qualitative study using interpretative phenomenological analysis
}

\author{
Seada A Kassie (D) , ${ }^{1,2}$ Jannat Alia, ${ }^{3}$ Lynda Hyland (D) ${ }^{2}$
}

To cite: Kassie SA, Alia J, Hyland L. Biopsychosocial implications of living with multiple sclerosis: a qualitative study using interpretative phenomenological analysis. BMJ Open 2021;11:e049041. doi:10.1136/ bmjopen-2021-049041

- Prepublication history for this paper is available online. To view these files, please visit the journal online (http://dx.doi. org/10.1136/bmjopen-2021049041).

Received 14 January 2021 Accepted 08 August 2021
A) Check for updates

(c) Author(s) (or their employer(s)) 2021. Re-use permitted under CC BY-NC. No commercial re-use. See rights and permissions. Published by BMJ.

${ }^{1}$ Shared Clinical Services, American Center for Psychiatry and Neurology, Abu Dhabi, UAE ${ }^{2}$ Psychology, Middlesex University Dubai, Dubai, UAE ${ }^{3}$ Department of Neurology, American Center for Psychiatry and Neurology, Abu Dhabi, UAE

Correspondence to

Seada A Kassie;

s.kassie@mdx.ac.ae

\section{ABSTRACT}

Background Multiple sclerosis (MS) is estimated to affect 2.8 million people worldwide, with increasing prevalence in all world regions (Walton et a). While there is no cure for MS, medication and lifestyle modifications can slow disease progression and enhance patients' quality of life. The biopsychosocial model of health recognises important interactions among biological, psychological and social factors in illness, including those relating to illness management, which contribute to the experience of those diagnosed with MS.

Objective This qualitative, idiographic study aimed to explore the lived experiences of patients in the United Arab Emirates (UAE) diagnosed with MS.

Methods Semistructured interviews were conducted with a purposive sample of eight patients with MS ranging in age from 25 to 56 years. All participants were residing in the UAE at the time of data collection. Interpretative phenomenological analysis was used to analyse the data. Results Three superordinate themes were identified from patients' candid accounts of their lives with MS, highlighting issues of illness management, acceptance and gratitude, and adaptive coping. These themes broadly illustrate biological, psychological and social aspects of patients' MS experiences.

Conclusion The study emphasised the importance of adopting the biopsychosocial model to treat and manage MS. Additionally, it highlights the need for routine assessment and early, multidimensional approach with multidisciplinary team efforts to improve patients' quality of life.

\section{INTRODUCTION}

A chronic demyelinating disease of the central nervous system, multiple sclerosis (MS) is estimated to affect 2.8 million people worldwide, with increasing prevalence in all world regions. ${ }^{1}$ Although the exact cause of MS is still unknown, susceptibility to the disease is influenced by genetic, immunological and environmental factors. $^{2-6}$ MS occurs more frequently in areas farther from the equator, including Canada, Denmark, Australia and New Zealand. ${ }^{7}$ Although there is currently no cure for MS, treatments can help modify or

\section{Strengths and limitations of this study}

- This qualitative study highlights the experiences of people living with multiple sclerosis in the United Arab Emirates, which has received comparatively less research attention than in 'Western' countries.

- The idiographic approach permitted in-depth exploration of the participants' lived experiences, absent in previous quantitative accounts of the same topic in the United Arab Emirates.

- Given the qualitative nature of this study, generalisability of findings was not a focus of this research.

- The various personal and disease characteristics of participants may have introduced unforeseen heterogeneity into the sample.

slow disease progression, treat clinical exacerbations and generally improve overall health and physiological function. ${ }^{4}$ Lifestyle factors such as smoking and obesity are known to increase disability progression. ${ }^{8}$ In combination with disease-modifying medications, rehabilitation strategies can manage MS symptoms. Such rehabilitation programmes focus on treating physiological and cognitive deficits, designed to improve and maintain one's ability to perform daily life activities. ${ }^{10}$ Alongside biomedical treatment, studies increasingly highlight the need for a multidimensional approach with multidisciplinary team efforts to treat MS due to its complexity, unpredictability and the invisibility of some of its symptoms. ${ }^{11-13}$

The biopsychosocial (BPS) model, an approach to illness diagnosis and management, is guided by a multidimensional view of an illness's biomedical, psychological and social features. ${ }^{14}{ }^{15}$ In clear contrast with the biomedical model, the BPS model is both a philosophy and a medical paradigm that proposes the need for humanising and empowering patients through the use of empathy and compassion in medical 
practice. ${ }^{15}$ The model encourages attention to the complexities of interactions among physiological, psychological and social aspects of an illness in determining appropriate and effective responses to primary and secondary symptoms. Examples of psychosocial factors include mood, personality, behaviour, coping, social support, family relationships and socioeconomic factors. These factors contribute to the overall experience of patients diagnosed with MS. Various aspects of life with MS have been examined through a BPS lens, including pain, ${ }^{1617}$ fatigue, ${ }^{18} 19$ resilience ${ }^{20} 21$ and quality of life. ${ }^{12}$ While the disease is consistently associated with reduced quality of life, studies over several decades show that disease severity alone does not fully explain this. ${ }^{12} 2223$ Such arguments are consistent with the BPS model of health, which considers the simultaneous implication of biological, psychological, and social aspects to fully understand and appreciate the patient's subjective wellbeing, quality of life and overall functioning. ${ }^{12}$

Negative experiences of people living with MS have been identified across various BPS domains. These include self-enforced social distancing as a means of protection, ${ }^{24}{ }^{25}$ the impact of fatigue on communication, ${ }^{26}$ the disease's impact on perceived dignity ${ }^{27}$ and personal relationships. ${ }^{28}$ Irvine $e t a l^{29}$ discussed how identity is redefined following MS diagnosis, and how initial functional challenges can ameliorate over time, with adjustment to the condition. Similarly, Strickland $e t a l^{30}$ presented a phenomenological account of how people living with MS reflect on the transition from their prediagnosis to postdiagnosis selves and learn to live with their illness. The impact on one's sense of self might not be inevitable $^{3132}$; it may depend on the extent to which MS symptoms impact the daily roles that were integral to the person's prediagnosis life. ${ }^{32}$ Interestingly, some positives have been shown to emerge from diagnosis with chronic illness, including 'post-traumatic growth'. ${ }^{33}$ In MS, this includes diverse outcomes such as increased compassion and mindfulness, improvements in family relations and lifestyle, ${ }^{34}$ health gains and increased spirituality. ${ }^{35}$ Multiple studies have also examined quality of life, ${ }^{122} 23$ meaning-making ${ }^{31}$ and growth ${ }^{33}$ in individuals living with MS and other chronic illnesses.

In the United Arab Emirates (UAE) and the wider Middle East and North Africa (MENA) region, quantitative studies focusing on illness management and patient care services highlight the lack of a multidimensional approach using multidisciplinary teams in treating neurological disorders and common comorbidities. ${ }^{36}$ Unlike the western world, the MENA region is still limited in providing holistic care to patients with chronic illnesses. ${ }^{38-44}$ The current study aimed to qualitatively explore patients' individual accounts and subjective experiences of living with MS in the UAE. By doing so, the objective was to solidify the need for a multidimensional approach to providing care in the UAE and the wider MENA region, which may enhance patients' quality of life ${ }^{3637}$ In this study, the term multidimensional refers to the provision of patient care using the BPS model of health. By looking at person-specific factors and the concept of health in more depth than merely viewing it as the absence of illness, an insight into how people navigate their lives with this chronic illness may be gained. Through a phenomenological approach, the study explored factors that may play a substantial role in determining the quality of life and overall adjustment of patients living with MS in the UAE.

\section{METHODS}

\section{Design}

This study used a qualitative, idiographic approach to explore participants' experiences of living with MS. A phenomenological approach informed all aspects of the study, from conceptualisation to data collection, analysis and presentation of findings. Through this window into the subjective, lived experiences of participants, it is possible to identify new meanings, which can inform how these experiences are understood by health professionals. ${ }^{45}$

\section{Sampling and participants}

Researchers recruited a small, homogeneous, purposively selected sample as per the requirements of interpretative phenomenological analysis (IPA). ${ }^{46}$ The study included eight participants diagnosed with MS (International Classification of Diseases (ICD-10: G35) using the McDonald diagnostic criteria. ${ }^{47}$ They ranged in age from 25 to 56 years and were representative of patients living with the same type of condition in the same geographic location. In addition to a clinical diagnosis of MS, the inclusion criteria were that participants were over 18 years and did not have other diagnosed neurological disorders. Demographic and clinical details of patients are given in table 1 .

\section{Data collection}

All participants provided informed consent. One-to-one, semistructured interviews were conducted with participants at their preferred location. Semistructured interviews are compatible with the chosen analysis, ${ }^{48}$ allowing the participants and the researcher to explore new, potentially unexpected discussion topics. Interviews, lasting approximately $30 \mathrm{~min}$, were audiorecorded and were carried out by SAK, a clinical research professional with background in psychology. The interviews consisted of nine questions, allowing for prompts. The interview guide is provided in figure 1.

\section{Data analysis}

The idiographic approach of IPA ${ }^{4649}$ was used to analyse the data. This iterative process involved familiarisation with data, identification of descriptive, linguistic, and conceptual codes, and the development of emergent themes and superordinate themes per case. These steps were repeated for each participant. Once completed, a master table of superordinate themes was identified for 
Table 1 Demographic and clinical characteristics of participants

\begin{tabular}{|c|c|c|c|c|c|}
\hline Pseudonym & Sex & Age range & Country of origin & $\begin{array}{l}\text { Time since diagnosis } \\
\text { (in years) }\end{array}$ & Comorbidities \\
\hline Anna & $\mathrm{F}$ & $25-34$ & USA & 3 & $\begin{array}{l}\text { Hypertension } \\
\text { Major depressive disorder } \\
\text { Generalised anxiety disorder } \\
\text { Panic disorder } \\
\text { Cognitive deficit } \\
\text { Vitamin D deficiency }\end{array}$ \\
\hline Maya & $\mathrm{F}$ & $35-44$ & United Arab Emirates & 4 & $\begin{array}{l}\text { Anaemia } \\
\text { Generalised anxiety disorder } \\
\text { Mild cognitive deficit } \\
\text { Vitamin D deficiency }\end{array}$ \\
\hline Imad & M & $35-44$ & Iraq & 6 & None \\
\hline Rashid & M & $25-34$ & Kingdom of Saudi Arabia & 10 & $\begin{array}{l}\text { Major depressive disorder } \\
\text { Vitamin D deficiency }\end{array}$ \\
\hline Batool & $\mathrm{F}$ & $35-44$ & United Arab Emirates & 1 & $\begin{array}{l}\text { Hyperthyroidism } \\
\text { Adjustment disorder } \\
\text { Mild cognitive deficit } \\
\text { Vitamin D deficiency }\end{array}$ \\
\hline Killian & M & $25-34$ & Ireland & 6 & $\begin{array}{l}\text { Major depressive disorder } \\
\text { Anxiety disorder }\end{array}$ \\
\hline
\end{tabular}

the group. Researchers adopted a data-driven analytical approach and findings were viewed in light of the BPS model of health. Doing so allowed the researchers to explore, in-depth, the lived experiences of participants. ${ }^{50}$ LH, a chartered psychologist, conducted data analysis in Microsoft Word. The findings were subsequently audited by SAK. The coconstruction of meaning and the double hermeneutic of IPA (wherein the researchers make sense of how the participants reflect on their own experiences) was intrinsic to this study. Both researchers engaged in critical reflexivity to examine how their own experiences and expectations might impact the analytical process to

1. Please tell me about your experiences of living with MS (Prompts: A typical day, aspects of life that MS has impacted).

2. What, for you, are the most challenging aspects of life with MS? (Prompts: Specific symptoms such as pain or fatigue, and/or limitations due to the illness).

3. How do these challenges impact you and your life? (Prompts: Occupational, social, physical functioning, general wellbeing)

4. Can you please discuss some strategies you use to manage these aspects of MS? (Prompts: Positive thinking, social support, medical professional support, adherence to treatment, nutrition, exercise).

5. Please tell me about how well you believe you are managing MS. (Prompt: How effective do you think these strategies are in helping you to manage MS?)

6. What, if anything, would help you to better manage MS in your daily life?

7. What does quality of life mean to you? (Prompt: What is your personal definition of quality of life?)

8. In what ways, if any, has your overall quality of life changed since your MS diagnosis? (Prompt: What are the most meaningful things in your life now versus before your diagnosis?)

9. Thank you very much for your participation in this research. Is there something that you think I should have asked, or that you would like to share? Would you like to add anything else?

Figure 1 Interview questions and prompts. ensure that the participants' voices were heard. Additionally, rigour of this study was enhanced in consultation with the Consolidated Criteria for Reporting Qualitative Research checklist. ${ }^{51}$

\section{Patient and public involvement}

Patients and the public were not involved in the design or conduct of this study.

\section{RESULTS}

Respondents spoke candidly about their experiences of living with MS, discussing issues ranging from symptom management to perceptions of quality of life, and the types of support they received. Three superordinate themes were identified-'Acceptance and management', 'Counting one's blessings' and 'Living differently'.

\section{Acceptance and management}

Participants varied greatly in their self-reported illness management. The heterogeneity of experiences is unsurprising, given that MS does not have a single, simple trajectory. Symptoms experienced by some (eg, fatigue, balance issues, numbness), were absent for others. Several patients engaged in a range of positive health behaviours, and all but one reportedly took disease-modifying therapies (DMTs); they attributed physical and psychological improvements to their adherence to treatment and a 
change in their overall attitude towards their diagnoses. However, others reported non-adherence with central components of their treatment regimen, including not taking their medication as prescribed. One participant struggled with MS to an extreme extent, across physical, psychological and social domains, whereas several others displayed adjustment and acceptance. Their varying experiences of illness management are explored in this section.

Participants who had high expectations of their illness management were self-critical when they believed they did not reach this ideal. This was particularly evident among those who actively researched their condition, potential treatment options, and who made lifestyle changes. Several participants reported positive outcomes from attending physiotherapy or from self-directed exercise. Lokesh's case illustrates this; discussing his engagement in physical activity as providing therapeutic benefits, he criticises his consistency:

Lokesh: I should be doing more exercise. I do yoga, I do meditation. That helps in flexibility.

Interviewer: You've seen results?

Lokesh: I see results when I don't do it for a while, I could feel that I'm much worse.

Interviewer: I see. How long have you been doing this?

\section{Lokesh: Since the beginning.}

Even if self-critical, Lokesh's MS management, which began at the time of diagnosis, demonstrates an active coping style. Unlike some other participants, his early focus on treatment and his beliefs about its effectiveness may have helped Lokesh come to terms with his diagnosis. Throughout his interview, he projects an image of someone mindful of the illness's demands, but who strives towards the best possible life with MS.

This drive towards health is shown by others, for example, Imad. The year following his diagnosis was characterised by anxiety about death. However, the health behaviours he initiated brought about a positive sense of self: 'I went like freakishly healthy for about six months... I stopped smoking, I stopped drinking.' His use of the term 'freakish' alludes to his belief that he went too far, although he suggested that this is a typical reaction after MS diagnosis. While Imad notes that he does not exercise as much as in his early postdiagnosis days, he continues to engage in positive health behaviours.

I try to run three times a week. The only one I do consistently is my long run on Friday morning because it's Friday morning. I wake up, my wife and my kid are still passed out, and I go for my run. I think that's the best thing.

Recognising the physical and psychological well-being benefits of lifestyle change, Imad advocates: 'Nutrition, exercise is key. Exercise is key, I'm telling you. Anyone who has MS, get off your ass and work out.'
Even when benefits were evident, engaging in positive health behaviours such as diet or physiotherapy was a challenge for some. Aliyah admitted giving up on physiotherapy, something that previously worked for her. Indeed, she believed that physiotherapy outperformed medication in treating her balance issue, stating 'it was REALLY good.' Although she stated that she had no free time after starting her postgraduate degree, she also admitted intentional non-adherence to the recommended treatment.

Aliyah: I never miss the pills. But with the injections, I used to (laughs).

Interviewer: You used to forget, okay.

Aliyah: Not forget. I used to intentionally miss it. I hated it... I used an auto-injector, and every time I took the injection I used to be scared, even though I did it so many times. I hated it...

Interviewer: Have any of your doctors recommended a special diet to you?

Aliyah: Yeah, I actually, I've actually seen one of the dieticians here and she recommends a specific diet, but I have not, uh, I haven't like, uh... done it. You know why? Because I hate it when I have to think about it.

Aliyah did not share her diagnosis with work colleagues, not wanting small mistakes she might make at work to be 'blamed on MS.' She further said that she hates it when people 'blame MS for everything', suggesting that this may be something she has encountered in other realms of her life. She believes that ignoring MS is a positive strategy in her illness management, stating "what I found good about myself is that I completely ignore that I have MS, like I completely ignore it, I think this helps.' This type of avoidant coping was evident to varying degrees among four of the eight interviewees. By choosing to not think about MS or adopt lifestyle changes recommended by healthcare providers, they believed they retained a greater semblance of 'normal', old selves.

Rashid's experience was markedly different; he neither coped actively nor was he able to ignore the physical and psychological toll MS had on his life. By his admission, he struggled to manage his MS:

It almost feels like I'm helpless. I'm having a vision problem. I used to drive cars, but now I can't. The balance and the depression is like a big... it's a big deal. And I'm just trying to live. The problems affect me in a bad way... I don't know what's wrong, is it MS, or... Even when I feel happy it just feels like seconds.

With marked deterioration in his health, including major depressive disorder and loss of sight and balance, he shared his perception of obstacles that impacted his MS management. He no longer took DMT, citing the cost as prohibitive. However, he also alluded to side effects as a reason for stopping both MS therapy-'... it was almost like giving me a heart attack, so it was not working'-and 
treatment for his clinical depression-'...I was like killing myself slowly.'

At the time of his interview, Rashid's only regular interactions were with his sole supporter, his mother-'She's my life actually. She's my motivation, you know, to be alive.' It was evident that Rashid had lost hope. Indeed, his story was characterised by loss-the loss of a young man's social life, truncated education opportunities, and an ever-shrinking lifeworld. Describing himself as peaceful and quiet, but also as helpless and without friends, there was resignation in his narrative.

Contrasting the concept of loss, other accounts demonstrated growth after diagnosis. Acceptance and management may be initially challenging, but can improve over time. Anna shared encouraging feedback she received.

[The support group leader told me] 'I've really seen a change in you this past couple of years, seeing you blossom. Taking charge of, managing your MS, vs just it being something that you were up against." So, I can, I can say now, that I am doing a better job at managing it. But it's not perfect, you know, it's really hard.

The support group leader's words acknowledged Anna's efforts and reassured her that she was on the right path. There was a sense that, for Anna, management was a process rather than an attainable, final state. She recognised that setbacks would happen, but that these would not defeat her. Anna's change was not merely in the shift from life before MS to life after MS, but rather in her incremental MS management improvements over time.

\section{Counting one's blessings}

Participants' narratives touched on their outlook on life with MS and the resultant changes in their interpersonal relationships. While all noted the impact of MS on their psychological well-being and relationships-new roles were undoubtedly negotiated with family and friendsthe changes wrought by MS were not always viewed negatively.

Six participants viewed themselves as lucky in several ways and reported gratitude for 'blessings' in their lives. Primarily, they appreciated support from family, friends, work colleagues, healthcare providers and others living with MS. Participants juxtaposed their experiences of those who support them with those who do not. Immediate family members (parents, children, siblings, spouses) were often credited with being chief sources of support. In Batool's case, her husband is the central figure in her support network.

My husband-he understands what I'm going through. Not fully, but he tries his best. He already let's say (took) off some of my responsibilities, uh, and whenever he feels like I need rest he will say to me 'just you go, I will do it.' So, he's really my main supporter.
She later elaborates on the redistribution of household responsibilities:

I have four kids, now I don't do everything for them, okay, previously I was doing A to Z for them. Now I try to keep them independent as well, and align my husband with the activities that they have. It's a responsibility that we both have.

This form of instrumental support allows Batool more time to rest and take care of her health. Identifying their 'shared' responsibility, she suggests that she and her husband are partners in their relationship and the management of her illness. Moreover, she appears to see an additional benefit in relinquishing some of her childcare responsibilities; her children have become more self-reliant.

It was apparent that family was not always a source of support. Killian, one of the younger people interviewed in this study recalled his father's immediate reaction to his diagnosis as 'you're going to $\mathrm{f}^{* * *}$ ing die, you're going to die.' The detail with which Killian recalled his father's words demonstrates the impact they had. There was an acute absence of support in Killian's family home in the 6 years following his diagnosis, which resulted in his development of non-familial networks of support, comprising colleagues and friends. Killian referred to himself as 'lucky' twelve times during his interview; reasons included his early diagnosis, the availability of effective medication, having a supportive work environment, and maintaining a positive attitude towards life with MS.

I'm lucky, because, you know stuff like, you're working, there're a lot of people with this ailment who are a lot worse. That in itself gives me some hope. Regardless of how anxious, what anxiety I have, I'm very lucky. That my treatment so far has been so good even through very tough times since my ailment, my diagnosis. So, I think I'm just thankful that I've been diagnosed when I was young, that's it. I think I'm just lucky.

Killian's maintenance of a positive outlook since his diagnosis was not easy for him. He refers to his innate tendency to view the glass as half empty and acknowledges difficulties in maintaining an optimistic outlook. Viewing himself as fortunate relative to others with the same condition perhaps offsets the negativity and lack of hope he encountered at the time of his diagnosis.

One participant, Maya, reported being thankful for the illness itself. She regarded her diagnosis as a turning point in her husband's relationship with God. A silver lining to her MS journey, she credited her illness with resolving his fractured faith.

I'm so happy, I'm actually so, so, so happy that I got MS. My husband has a 'faith issue', let's put it that way, and, because of MS, he got so much faith. Look, my husband loves me so much, and I love him so much. He was so devastated and broken to pieces, 
and he realized 'She got a disease that has no cure! That nobody can do anything about.' I couldn't walk. I literally couldn't walk. He had to carry me up and down the stairs... he was so broken apart and he realized the only one who could fix it is God! 'I better get back to him! I better get back on track.' I'm so happy, you have no idea!

This acknowledgement of her husband's devastation at her diagnosis is jarring when viewed alongside Maya's happiness, particularly in the context of their loving relationship. However, ascribing a positive dimension to the MS diagnosis may have allowed Maya to cope, see a 'bigger picture', and make meaning from her new identity.

\section{Living differently}

The contrast between participants' lives 'before' and 'after', connected only by a liminal period of symptoms, was shared by five participants; they reported their lives had significantly changed since the diagnosis. Most viewed their illness and the resultant lifestyle changes as a burden. For some, the demands of symptoms, treatment regimen, and the pressure to conform to healthy but restrictive lifestyles, were incompatible with the daily responsibilities that predated diagnosis.

Batool explained how the demands placed on her did not change after she was diagnosed with MS. She struggled to reconcile the two 'Batools'.

I don't want people to compare me with my previous life, when I didn't have MS. I did lots of changes in my life to accommodate myself with the disease. I just need people to understand that this is a new Batool, okay, that's been trying to develop herself. But do not compare me please with the previous Batool that had no MS in her life.

This dichotomised self and Batool's literal identification as a 'new' person with a previous life illustrates the extent of the change caused by MS. While she explicitly recognises this change, it is evident that she believes others do not. She suggested that continuous demands placed on her by others stem from a lack of awareness about MS, an illness she refers to as 'a monster in (my) head.' Despite pressure to be her old self, and live up to her old responsibilities, Batool listens to her body and the physical implications of MS such as fatigue:

I feel like my body is calling, I have to, you have to get shut down, to go to sleep. Because I need energy, so, people might not understand, like if, especially you have family commitment, and, uh, like you are escaping from this responsibility, but for me, I try to ignore it.

Although invisible to others, symptoms of MS, especially fatigue, impacted day-to-day activities. Like Batool, Anna regarded MS as resulting in an 'enforced slow-down'.

Cognitively it's had a huge impact on my memory and my ability to focus. On a bad day I'll get really terrible aphasia. Like, speaking as good as I am right now is a very good day for me (laughs), so, which is difficult when you're trying to do something like class, you know, or talk to other people and things of that nature... On a bad fatigue day, I may spend all day napping, crawled up with my cats, and I always really feel guilty because I'm not able to do any housework or anything like that. But it's also something that I've come to accept, that every now and then I'm just going to have a bad day like it's just going to happen.

Previously minor activities were celebrated: 'Hey, I have the energy to go out and meet with my friends. That's fantastic, that means a lot to me.' Although Anna reports feeling guilty because of her inability to manage some responsibilities, she shows a pragmatic acceptance of what she can and cannot do.

Diagnosed shortly after completing high school, Aliyah's entire adult life has been impacted by MS. She shared that she did not have the opportunity to experience early adulthood in the same way as her peers. For example, she did not learn to drive, partially due to fears regarding balance, her most prevalent MS symptom. Despite asserting that she can still do the things she used to, Aliyah acknowledges a need to 'think' about her activities: 'Before I wouldn't think about it I would just take the stairs, now I have to think about it, like okay, how is my balance now, how is everything now? I have to, like, think about it.' Apart from curtailing the independence associated with young adulthood, the absence of this rite of passage differentiates her from her peer group (those without MS) and others diagnosed with MS at a later age.

The experiences of participants illustrated above contrast with those of Killian, Lokesh and Imad, who acknowledge the challenges posed by MS, but refuse to be defined by their diagnosis. Killian reportedly experienced MS symptoms throughout his early life and was habituated to what he termed as the 'fuzzy' or 'sticky' sensation of MS. He did not indicate that the diagnosis changed his life course. Having lived with symptoms for several years before his diagnosis, he said 'I don't consider (MS) a disability, I don't consider that an anomaly, I know how to go about my normal life. I stayed on a job, I went to university with it, it was normal.' While he identifies difficulties in life with this condition, he did not believe that MS should define his identity. He advises that others “... don't let the MS consume you. It's, it's partially life. You have to manage it but it shouldn't be the centre of your life.'

Lokesh also references the concept of normality, although a 'new normal', while acknowledging that his life has changed since the diagnosis:

Obviously you can't do much, as much as you'd like to, in terms of exercise, in terms of walking, in terms of interacting with people. It's not that I withdraw socially, but I avoid too much interaction. I get tired. I feel like I need time for myself. 
Even though the physical implications of MS were apparent in his case (he had impaired gait and balance issues), he claimed 'I don't feel different. I behave and think normally. It's just that physically you might not look the same.' Lokesh says that his physical appearance as someone with an evident disability does not bother him, 'I don't really care about what people think.'

Inner strength helps Imad, who views himself as someone who actively confronts life's challenges. A selfprofessed optimist and extrovert, his attitude helped him deal with the shock of the diagnosis and manage the condition in the longer term.

I think I have a character of, you know, get things done. Get knocked down, get back up, do it again. I'm an entrepreneur, you know I've started my own business. It's not easy, it's not my first business, so, you know it's a challenge that you have to take. You have two options, right? Either you're going to sit there and cry in the corner, or you're going to go do something about it, so I get up and do something about it.

Participants' subjective experiences highlight variability in life with MS. Most, irrespective of the myriad symptoms, were practical in their outlook, recognising limitations but getting on with their lives. The psychological, physical and social impacts of MS were evident in narratives around change or, conversely, determined allegiance to prediagnosis identities.

\section{DISCUSSION}

This study explored the subjective experiences of patients living with MS in the UAE. An interpretative phenomenological approach ${ }^{49}$ was used to analyse participants' transcribed interviews from which three superordinate themes emerged. These are 'Acceptance and management', 'Counting one's blessings' and 'Living differently'. The themes exhibited the participants' varied, subjective experiences of living with MS, but they also highlighted commonalities in physiological, psychological and social factors that characterise life with this chronic illness.

Under the theme of 'acceptance and management', participants touched on coming to terms with their diagnosis and dealing with the changes in their day-to-day lives due to physiological limitations caused by MS. ${ }^{29-32}$ Some achieved benefits from attending physiotherapy sessions to alleviate the physical symptoms, such as difficulties in balance and walking. All but one participant were on DMTs at the time of data collection, with some taking additional measures (eg, setting phone reminders for medication and implementing a strict exercise schedule) to adhere to their treatment. The theme 'counting one's blessings' showcases how MS affected participants in both family and social circles. The impact of having (or not having) family or social support was palpably seen in almost all participants' accounts, and is similarly evident in previous accounts within Western contexts. ${ }^{33}{ }^{34}$ Those who reported family and social support viewed this as indispensable to their management of MS. Identity redefinition and self-prioritisation were noticeable in the theme 'living differently', wherein participants, to varying degrees, came to terms with their new postdiagnosis realities. In some cases, participants had to carve out time and space for themselves, previously dedicated to other priorities. Personal attributes helped in this transition to a new life. Traits such as self-efficacy, self-acceptance and adaptive coping seemed to counteract negative illness perceptions and, in some cases, non-adherence to treatment plans. This was also evident in previous studies wherein self-efficacy and locus of control were determinants of health status, adherence to treatment, disease management, adjustment and health-related quality of life. ${ }^{52-56}$ Strober ${ }^{12}$ found that quality of life was positively associated with adaptive coping, perceived social support, self-efficacy and locus of control, and negatively associated with primary and secondary symptoms. Psychosocial adjustment to MS takes time; it is influenced by the self and by others, and it can impact the uptake of rehabilitative opportunities. ${ }^{295758}$ While the three identified themes are discussed separately, the biological, psychological and social elements in the lives' of the participants were found to interact and often even overlap. The close and often complex interaction of biological, psychological and social factors in the participants' journey is indicative of the need for a multidimensional approach involving multidisciplinary team efforts to support patients with MS.

The BPS model proposes the simultaneous consideration of biological, psychological and social aspects of illness to fully understand and appreciate the patient's subjective well-being, quality of life and overall functioning. ${ }^{14} 15$ As reported in previous studies, ${ }^{12} 1718$ a multidimensional approach with multidisciplinary team efforts is optimal to alleviating symptoms experienced by patients with MS, both primary and secondary. As evident among the current sample, fatigue was a prevalent, primary MS symptom. ${ }^{59}$ Fotigue can be debilitating; although it can interfere with life in professional and personal spheres, participants report that this symptom, similar to other invisible symptoms of MS, is not always recognised by others. ${ }^{13}$ Indeed, according to Ayache and Chalah ${ }^{61}$ fatigue is frequently overlooked in clinical practice despite its high prevalence. While aware of the symptoms, clinicians may not fully appreciate the extent of its impact on patients. ${ }^{62}{ }^{63}$ Secondary or comorbid symptoms of MS include psychosocial factors such as depression, ${ }^{64}$ anxiety, ${ }^{64}$ unemployment due to physical dysfunction ${ }^{65}$ or cognitive impairment, ${ }^{6667}$ reduced quality of life ${ }^{68-72}$ and reduced subjective well-being. ${ }^{12}$ Wollin $e t a l^{70}$ found that depression, anxiety, self-efficacy, social support and stress explain $40 \%$ of the variance in quality of life when disease severity and duration were accounted for. Depression in MS is estimated at $30 \%$, with anxiety around $22.1 \% .{ }^{64}$ The current sample included three people with a clinical diagnosis of major depressive disorder and four with general anxiety disorder. Implications of psychiatric 
comorbidities include limited opportunities for employment, ${ }^{65}$ signalling a clear need to optimise patient care (eg, through provision of comprehensive psychological support). Additionally, patients with MS with cognitive impairment may face difficulty in finding/maintaining employment and engaging in social activities. ${ }^{66} 677172 \mathrm{In}$ particular, two participants' accounts of cognitive and physical impairment showed a stark impact on their social and occupational functioning. Some participants in the current sample expressed how much they value support from family and friends; often, a lack of MS awareness on the part of family members caused challenges for them. Particularly in the UAE and the wider MENA region, it is pertinent to increase public awareness through education/awareness campaigns and set up social support groups in healthcare facilities to reduce misconceptions about MS $^{36} 39$ and to indirectly facilitate illness management. ${ }^{73}$ These findings, along with previous quantitative studies focusing on common primary and secondary MS symptoms affecting the general and health-related quality of life, emphasise the importance of a holistic approach to treating and managing MS. ${ }^{3637}$ These and other similar studies highlight the importance of routine assessment and early, effective intervention in MS using the BPS model.

\section{Limitations}

The study is not without limitations. Although the study team aimed for sample homogeneity, it became evident throughout the interview process that there were clear differences among the subjects in terms of both disease characteristics and individual circumstances that may have introduced unforeseen heterogeneity to the sample. These differences include MS types, length of time since diagnosis, family dynamics, access to care and treatment for comorbid conditions. For example, clinically diagnosed psychiatric and cognitive comorbidities were present in six out of the eight participants, including general anxiety disorders, major depressive disorder, adjustment disorder, mild cognitive deficit and mild memory deficit. Some participants were already receiving pharmacological and psychological treatment for the said comorbidities. As a result, we propose careful interpretation of the results keeping such differences within context. Nevertheless, the heterogeneity observed in the sample is also representative of the characteristics of MS as a chronic illness; no two individuals are the same, even when carrying the same diagnosis.

\section{Future research directions}

This study focused on a small sample of UAE-based people living with MS. In light of how social support enhanced the participants' illness management, further research attention should be directed towards perceived social stigma and invisible symptoms of MS, such as fatigue, pain, sleep disturbances and cognitive impairment. While fatigue was the most commonly reported symptom in the current study, pain is reported by approximately
$65 \%-92 \%$ of patients. ${ }^{74-77}$ Given that chronic pain has been shown to impact self-identity and increase the likelihood of self-isolation, ${ }^{76}$ it may negatively affect psychological well-being and MS management. Sleep disturbances are prevalent among those with $\mathrm{MS},{ }^{77}$ as is cognitive impairment. ${ }^{67} 67$ The hidden nature of these symptoms can result in family members, friends and employers showing limited understanding of MS patients' need to 'live differently', postdiagnosis. ${ }^{13} 73$ Future research may explore potential bidirectional relationships between psychosocial factors and such invisible symptoms, and the resultant impact on coping and quality of life.

\section{IMPLICATIONS AND CONCLUSION}

This qualitative study offers a unique insight into patients' lived experiences with MS and a deeper understanding of the need for a multidimensional approach to managing this chronic illness. Practitioners working with patients who have MS may consider the transferability of these findings. Within the clinical setting, a multidisciplinary team approach (from initial diagnosis to longterm management) is optimal to address primary and secondary symptoms experienced by patients with MS. Clinical care providers could enhance existing provision to accommodate the multidimensional needs of patients with MS by enhancing patient care services, particularly psychological/psychiatric treatments and supports. Through such advancements, it is hoped that health outcomes and quality of life for patients living with MS can be significantly improved.

Acknowledgements The authors would like to acknowledge and thank Dr. Alia Ammar, Clinical Neuropsychologist at the American Centre for Psychiatry and Neurology for facilitating the interview process by giving the research team access to the MS support group.

Contributors All authors have contributed to the study and the preparation of this manuscript following the ICMJE authorship criteria. SAK contributed to designing the study, preparing and submitting documents to the IRB and securing approval, collecting and transcribing data, auditing the analysis and writing up the manuscript. LH contributed to designing the study, analysing data and writing up the manuscript. JA contributed to contacting the patients for the interviews, arranging the interviews and critically reviewing the manuscript.

Funding The authors have not declared a specific grant for this research from any funding agency in the public, commercial or not-for-profit sectors.

Competing interests None declared.

Patient and public involvement Patients and/or the public were not involved in the design, or conduct, or reporting, or dissemination plans of this research.

Patient consent for publication Not required.

Ethics approval The study was reviewed and approved by the Institutional Review Board of the American Centre for Psychiatry and Neurology, UAE (reference number: ACPN-IRB-PN-0030).

Provenance and peer review Not commissioned; externally peer reviewed.

Data availability statement Data are available on reasonable request. Data will not be shared, but reasonable requests may be directed to the corresponding author.

Open access This is an open access article distributed in accordance with the Creative Commons Attribution Non Commercial (CC BY-NC 4.0) license, which permits others to distribute, remix, adapt, build upon this work non-commercially, and license their derivative works on different terms, provided the original work is 
properly cited, appropriate credit is given, any changes made indicated, and the use is non-commercial. See: http://creativecommons.org/licenses/by-nc/4.0/.

ORCID iDs

Seada A Kassie http://orcid.org/0000-0001-6546-6168

Lynda Hyland http://orcid.org/0000-0001-5813-6400

\section{REFERENCES}

1 Walton C, King R, Rechtman L, et al. Rising prevalence of multiple sclerosis worldwide: insights from the atlas of MS, third edition. Mult Scler 2020;26:1816-21.

2 Milo R, Kahana E. Multiple sclerosis: geoepidemiology, genetics and the environment. Autoimmun Rev 2010;9:A387-94.

3 Mokry LE, Ross S, Ahmad OS, et al. Correction: vitamin D and risk of multiple sclerosis: a Mendelian randomization study. PLoS Med 2016;13:e1001981.

4 National Multiple Sclerosis Society. Definition of MS, 2016. Available: https://www.nationalmssociety.org/What-is-MS/Definition-of-MS

5 Olsson T, Barcellos LF, Alfredsson L. Interactions between genetic, lifestyle and environmental risk factors for multiple sclerosis. Nat Rev Neurol 2017;13:25

6 Sintzel MB, Rametta M, Reder AT. Vitamin D and multiple sclerosis: a comprehensive review. Neurol Ther 2018;7:59-85.

7 Simpson S, Wang W, Otahal P, et al. Latitude continues to be significantly associated with the prevalence of multiple sclerosis: an updated meta-analysis. J Neurol Neurosurg Psychiatry 2019;90:1193-200.

8 Paz-Ballesteros WC, Monterrubio-Flores EA, de Jesús FloresRivera J, et al. Cigarette smoking, alcohol consumption and overweight in multiple sclerosis: disability progression. Arch Med Res 2017;48:113-20.

9 Rosso M, Chitnis T. Association between cigarette smoking and multiple sclerosis: a review. JAMA Neurol 2020;77:245-53.

10 Gallien P, Gich J, Sánchez-Dalmau BF, et al. Multidisciplinary management of multiple sclerosis symptoms. Eur Neurol 2014;72 Suppl 1:20-5.

11 Michalski D, Liebig S, Thomae E, et al. Pain in patients with multiple sclerosis: a complex assessment including quantitative and qualitative measurements provides for a disease-related biopsychosocial pain model. J Pain Res 2011;4:219-25.

12 Strober LB. Quality of life and psychological well-being in the early stages of multiple sclerosis (MS): importance of adopting a biopsychosocial model. Disabil Health J 2018;11:555-61.

13 Parker L-S, Topcu G, De Boos D, et al. The notion of "invisibility" in people's experiences of the symptoms of multiple sclerosis: a systematic meta-synthesis. Disabil Rehabil 2020:1-15.

14 Engel GL. The clinical application of the biopsychosocial model. Am J Psychiatry 1980;137:535-44.

15 Borrell-Carrió F, Suchman AL, Epstein RM. The biopsychosocial model 25 years later: principles, practice, and scientific inquiry. Ann Fam Med 2004:2:576-82.

16 Kerns RD, Kassirer M, Otis J. Pain in multiple sclerosis: a biopsychosocial perspective. J Rehabil Res Dev 2002;39:225-32.

17 Kerns RD. Psychosocial aspects of pain. Int J MS Care 2002;2:35-8.

18 Wijenberg MLM, Stapert SZ, Köhler S, et al. Explaining fatigue in multiple sclerosis: cross-validation of a biopsychosocial model. $J$ Behav Med 2016;39:815-22.

19 Newton G, Griffith A, Soundy A. The experience of fatigue in neurological patients with multiple sclerosis: a thematic synthesis. Physiotherapy 2020;107:306-16.

20 Black R, Dorstyn D. A biopsychosocial model of resilience for multiple sclerosis. J Health Psychol 2015;20:1434-44.

21 Kasser SL, Zia A. Mediating role of resilience on quality of life in individuals with multiple sclerosis: a structural equation modeling approach. Arch Phys Med Rehabil 2020;101:1152-61.

22 Koch LC, Rumrill Phillip D., Jr., Roessler RT, et al. Illness and demographic correlates of quality of life among people with multiple sclerosis. Rehabil Psychol 2001;46:154-64.

23 Pfennings L, Cohen L, Adèr $\mathrm{H}$, et al. Exploring differences between subgroups of multiple sclerosis patients in health-related quality of life. J Neurol 1999;246:587-91.

24 Grytten N, Måseide P. 'When I am together with them I feel more III.' the stigma of multiple sclerosis experienced in social relationships. Chronic IIIn 2006;2:195-208.

25 Al-Sharman A, Khalil H, Nazzal M, et al. Living with multiple sclerosis: a Jordanian perspective. Physiother Res Int 2018;23:e1709.

26 Blaney BE, Lowe-Strong A. The impact of fatigue on communication in multiple sclerosis. The insider's perspective. Disabil Rehabil 2009;31:170-80.
27 Lohne V, Aasgaard T, Caspari S, et al. The Lonely battle for dignity: individuals struggling with multiple sclerosis. Nurs Ethics 2010;17:301-11.

28 Strickland K, Worth A, Kennedy C. The experiences of support persons of people newly diagnosed with multiple sclerosis: an interpretative phenomenological study. J Adv Nurs 2015;71:2811-21.

29 Irvine H, Davidson C, Hoy K, et al. Psychosocial adjustment to multiple sclerosis: exploration of identity redefinition. Disabil Rehabil 2009;31:599-606.

30 Strickland K, Worth A, Kennedy C. The liminal self in people with multiple sclerosis: an interpretative phenomenological exploration of being diagnosed. J Clin Nurs 2017;26:1714-24.

31 Mozo-Dutton L, Simpson J, Boot J. MS and me: exploring the impact of multiple sclerosis on perceptions of self. Disabil Rehabil 2012;34:1208-17.

32 Desborough J, Brunoro C, Parkinson A, et al. 'It Struck at the heart of who I thought I was': a meta-synthesis of the qualitative literature examining the experiences of people with multiple sclerosis. Health Expect 2020;23:1007-27.

33 Zeligman M, Varney M, Grad RI, et al. Posttraumatic growth in individuals with chronic illness: the role of social support and meaning making. J Counsel Dev 2018;96:53-63.

34 Lex H, Weisenbach S, Sloane J, et al. Social-emotional aspects of quality of life in multiple sclerosis. Psychol Health Med 2018;23:411-23.

35 Pakenham KI. The nature of benefit finding in multiple sclerosis (MS). Psychol Health Med 2007;12:190-6.

36 Alsaadi T, Kassie S, Mohamed Ali O, et al. Psychiatric comorbidity in neurological disorders: towards a multidisciplinary approach to illness management in the United Arab Emirates. Front Psychiatry 2019;10:263.

37 Bohlega S, Inshasi J, Al Tahan AR, et al. Multiple sclerosis in the Arabian Gulf countries: a consensus statement. J Neurol 2013;260:2959-63.

38 Alsaadi T, Kassie S, El Hammasi K, et al. Potential factors impacting health-related quality of life among patients with epilepsy: results from the United Arab Emirates. Seizure 2017;53:13-17.

39 Alsaadi T, Hammasi KE, Shahrour TM, et al. Depression and anxiety as determinants of health-related quality of life in patients with multiple sclerosis - United Arab Emirates. Neurol Int 2017;9:75-8.

40 Alkhadhari S, Alsabbrri AO, Mohammad IHA, et al. Prevalence of psychiatric morbidity in the primary health clinic Attendees in Kuwait. $J$ Affect Disord 2016;195:15-20.

41 Al-Otaibi B, Al-Weqayyan A, Taher H, et al. Depressive symptoms among Kuwaiti population attending primary healthcare setting: prevalence and influence of sociodemographic factors. Med Princ Pract 2007;16:384-8.

42 Al-Qadhi W, Ur Rahman S, Ferwana MS, et al. Adult depression screening in Saudi primary care: prevalence, instrument and cost. BMC Psychiatry 2014;14:190.

43 Alsaadi T, El Hammasi K, Shahrour TM, et al. Prevalence of depression and anxiety among patients with epilepsy attending the epilepsy clinic at Sheikh Khalifa medical City, UAE: a cross-sectional study. Epilepsy Behav 2015;52:194-9.

44 Sulaiman N, Hamdan A, Tamim H, et al. The prevalence and correlates of depression and anxiety in a sample of diabetic patients in Sharjah, United Arab Emirates. BMC Fam Pract 2010;11:80.

45 Neubauer BE, Witkop CT, Varpio L. How phenomenology can help us learn from the experiences of others. Perspect Med Educ 2019;8:90-7.

46 Smith J, Flowers P, Larkin M. Interpretative phenomenological analysis: theory, method and research. London: Sage, 2009.

47 McDonald WI, Compston A, Edan G, et al. Recommended diagnostic criteria for multiple sclerosis: guidelines from the International panel on the diagnosis of multiple sclerosis. Ann Neurol 2001;50:121-7.

48 Smith JA, Osborn M. Interpretive phenomenological analysis. In: Smith JA, ed. Qualitative psychology: a practical guide to research methods. London: Sage, 2003: 51-80.

49 Pietkiewicz I, Smith JA. A practical guide to using interpretative phenomenological analysis in qualitative research psychology. Psychol J 2014;20:7-14.

50 Smith JA, Osborn M. Interpretative phenomenological analysis as a useful methodology for research on the lived experience of pain. $\mathrm{Br}$ Pain 2015;9:41-2.

51 Tong A, Sainsbury P, Craig J. Consolidated criteria for reporting qualitative research (COREQ): a 32-item checklist for interviews and focus groups. Int J Qual Health C 2015;19:349-57.

52 Mohr DC, Boudewyn AC, Likosky W, et al. Injectable medication for the treatment of multiple sclerosis: the influence of self-efficacy expectations and injection anxiety on adherence and ability to selfinject. Ann Behav Med 2001;23:125-32. 
53 Motl RW, McAuley E, Snook EM. Physical activity and quality of life in multiple sclerosis: possible roles of social support, self-efficacy, and functional limitations. Rehabil Psychol 2007;52:143-51.

54 Schmitt MM, Goverover Y, Deluca J, et al. Self-Efficacy as a predictor of self-reported physical, cognitive, and social functioning in multiple sclerosis. Rehabil Psychol 2014;59:27-34.

55 Motl RW, Snook EM. Physical activity, self-efficacy, and quality of life in multiple sclerosis. Ann Behav Med 2008;35:111-5.

56 Wilski M, Brola W, Tomczak M. Health locus of control and mental health in patients with multiple sclerosis: mediating effect of coping strategies. Res Nurs Health 2019;42:296-305.

57 Koutsogeorgou E, Chiesi AM, Leonardi M. Social capital components and social support of persons with multiple sclerosis: a systematic review of the literature from 2000 to 2018. Disabil Rehabil 2020;42:3437-49.

58 Lexell EM, Lund ML, Iwarsson S. Constantly changing lives: experiences of people with multiple sclerosis. Am J Occup Ther 2009;63:772-81.

59 Fisk JD, Pontefract A, Ritvo PG, et al. The impact of fatigue on patients with multiple sclerosis. Can J Neurol Sci 1994;21:9-14.

60 Kaynak H, Altintaș A, Kaynak D, et al. Fatigue and sleep disturbance in multiple sclerosis. Eur J Neurol 2006;13:1333-9.

61 Ayache SS, Chalah MA. Fatigue in multiple sclerosis - insights into evaluation and management. Clin Neuropsychol 2017;47:139-71.

62 Decker MJ. Assessing fatigue in multiple sclerosis: shedding light on the elephant in the dark. Sleep 2010;33:1005-6.

63 Braley TJ, Chervin RD. Fatigue in multiple sclerosis: mechanisms, evaluation, and treatment. Sleep 2010;33:1061-7.

64 Boeschoten RE, Braamse AMJ, Beekman ATF, et al. Prevalence of depression and anxiety in multiple sclerosis: a systematic review and meta-analysis. J Neurol Sci 2017;372:331-41.

65 Wicks CR, Ward K, Stroud A, et al. Multiple sclerosis and employment: associations of psychological factors and work instability. J Rehabil Med 2016;48:799-805.

66 Amato MP, Zipoli V, Portaccio E. Multiple sclerosis-related cognitive changes: a review of cross-sectional and longitudinal studies. $J$ Neurol Sci 2006;245:41-6.
67 Jønsson A, Andresen J, Storr L, et al. Cognitive impairment in newly diagnosed multiple sclerosis patients: a 4-year follow-up study. $J$ Neurol Sci 2006;245:77-85.

68 Wilski M, Gabryelski J, Brola W, et al. Health-related quality of life in multiple sclerosis: links to acceptance, coping strategies and disease severity. Disabil Health J 2019;12:608-14

69 Gil-González I, Martín-Rodríguez A, Conrad R, et al. Quality of life in adults with multiple sclerosis: a systematic review. BMJ Open 2020;10:e041249.

70 Wollin JA, Spencer N, McDonald E, et al. Longitudinal changes in quality of life and related psychosocial variables in Australians with multiple sclerosis. Int J MS Care 2013;15:90-92.

71 Benedict RHB, Wahlig E, Bakshi R, et al. Predicting quality of life in multiple sclerosis: accounting for physical disability, fatigue, cognition, mood disorder, personality, and behavior change. J Neurol Sci 2005;231:29-34.

72 Schwartz C, Frohner R. Contribution of demographic, medical, and social support variables in predicting the mental health dimension of quality of life among people with multiple sclerosis. Health Soc Work 2005;30:203-12.

73 Lakin L, Davis BE, Binns CC, et al. Comprehensive approach to management of multiple sclerosis: addressing invisible Symptoms-A narrative review. Neurol Ther 2021;10:75-98.

74 Hirsh AT, Turner AP, Ehde DM, et al. Prevalence and impact of pain in multiple sclerosis: physical and psychologic contributors. Arch Phys Med Rehabil 2009;90:646-51.

75 Kassirer M. Multiple sclerosis and pain: a medical focus. Int J MS Care 2000;2:40-7.

76 Smith JA, Osborn M. Pain as an assault on the self: an interpretative phenomenological analysis of the psychological impact of chronic benign low back pain. Psychol Health 2007;22:517-34.

77 Merlino G, Fratticci L, Lenchig C, et al. Prevalence of 'poor sleep' among patients with multiple sclerosis: an independent predictor of mental and physical status. Sleep Med 2009;10:26-34. 